IJIS Indonesian Journal on Information System

\title{
PERANCANGAN SISTEM INFORMASI PENJUALAN SPAREPART MOTOR PADA CV. LION
}

\section{DESIGN OF INFORMATION SYSTEM ON MOTOR SPARE PARTS SALES CV. LION}

\author{
Yosep Yordan Mehdila ${ }^{1}$, Darman Umagapi ${ }^{2}$ \\ Program Studi Manajemen Informatika, \\ Politeknik Sains dan Teknologi Wiratama Maluku Utara \\ yosep_yordan04@gmail.com
}

\begin{abstract}
Abstrak
CV. LION sebagai salah satu perusahaan penjualan kendaraan bermotor, yang juga menyediakan sparepart yang tumbuh dan berkembang di kota ternate, proses pengelolaan data dan penjualan sparepart pada CV Lion masih bersifat konvesional, data penjualan sparepart diinput menggunakan Microsoft excel sehingga pada proses pencarian data penjualan membutuhkan waktu lama dikarenakan harus dibuka satu persatu data penjualan tersebut pada sheet - sheet dan pelanggan yang ingin melakukan pemesanan sparepart motor yang dicari harus datang ke CV Lion teersebut sehingga dianggap kurang efektif, Peniltian ini dilakukan pada CV Lion Kota Ternate bertujuan menunjang kinerja dan kegiatan perusahaan yang tadinya masih di lakukan secara konvesional, pengumpulan data diperoleh melalui observasi, wawancara, dokumentasi, Perancangan dan Implementasi, Sistem yang di rancang diharapkan mempermudah proses kerja admin dalam mengelola data penjualan dan pelanggan mendapatkan informasi tentang sparepart yang dicari pada sistem
\end{abstract}

\section{Kata Kunci : Perancangan, Sistem Informasi, Sparepart}

CV. LION as one of the company's sales of motor vehicles, which also provides spare parts that grow and flourish in the city of ternate, the process of data management and the sale of spare parts on the $C V$ accounting nature still, Lion sales data inputted spare parts using Microsoft Excel so that in the process of sales data takes a long time because should be opened one by one the sales data in a sheet-sheet and customers who would like to make a booking search motor spare parts should come to CV Lion exchanges so that is considered less effective Peniltian, this is done on a CV Lion Ternate city aims to support the performance and activities of the company, who had still done in conservation, collection of data obtained through observation, interviews, documentation, design and implementation, the system is designed is expected to facilitate work process admin in managing sales data and customers get information about car part you're looking for on the system

\section{Keyword: Design, Information System, Sparepart}

\section{PENDAHULUAN}

Di era globalisasi sekarang ini, kemajuan teknologi informasi sudah semakin canggih. Hal ini berdampak pada kemudahan akses transaksi di segala bidang usaha, seperti jual beli sparepart (suku cadang) motor. Data menunjukkan jumlah penjualan motor di indonesia mencapai 7 juta unit/ tahun (Asosiasi Sepeda Motor Indonesia). Peningkatan jumlah kendaraan bermotor ini pasti 
diikuti dengan permintaan suku cadang motor yang semakin tinggi

Setiap perusahaan yang bergerak dibidang penjualan motor harus mampu menjawab semua masalah kerusakan motor yang terjadi dengan menyediakan suku cadang motor yang maksimal agar bisa sebanding dengan kasus yang nantinya terjadi.

CV. LION sebagai salah satu perusahaan penjualan kendaraan bermotor, yang juga menyediakan sparepart yang tumbuh dan berkembang di kota ternate, proses pengelolaan data dan penjualan sparepart pada CV Lion masih bersifat konvesional, data penjualan sparepart diinput menggunakan Microsoft excel sehingga pada proses pencarian data penjualan membutuhkan waktu lama dikarenakan harus dibuka satu persatu data penjualan tersebut pada sheet - sheet dan pelanggan yang ingin melakukan pemesanan sparepart motor yang dicari harus datang ke $\mathrm{CV}$ Lion teersebut sehingga dianggap kurang efektif

Perkembangan Teknologi Informasi perlu memanfaatkan sistem yang terkomputerisasi yaitu dengan merancang system penjualan sparepart motor pada CV.Lion, sehingga dapat menunjang kinerja dan kegiatan perusahaan sehingga dapat mempermudah proses kerja admin dan pelanggan mendapatkan informasi tentang sparepart dan dapat melakukan pemesanan melalui system tersebut, tanpa harus datang ke CV Lion, system yang dirancang menggunakan bahasa php, html dan database MySql.

\section{Rumusan Masalah}

Berdasarkan latar belakang di atas, maka masalah dalam penelitian ini di rumuskan sebagai berikut: Bagaimana merancang sistem informasi penjualan sparepart motor pada CV Lion Ternate? Tujuan penelitian ini Diharapkan System yang dirancang dapat menunjang kinerja dan kegiatan perusahaan sehingga dapat mempermudah proses kerja admin dan pelanggan mendapatkan informasi tentang sparepart yang dicari

\section{LANDASAN TEORI \\ Defenisi Sistem Informasi}

Berdasarkan pengertian sistem dan informasi, maka suatu sistem informasi adalah suatu sistem dalam suatu organisasi yang mempertemukan kebutuhankebutuhan pengolahan transaksi harian, mendukung operasi, bersifat manajerial dan kegiatan strategi dari suatu organisasi dan menyediakan pihak luar tertentu dengan laporan-laporan yang diperlukan. Sistem informasi didefinisikan menjadi "Data yang diolah menjadi bentuk yang lebih berguna dan lebih berarti bagi penerimanya" (Jogiyanto 1999:8).

\section{Karateristik Sistem}

Ada pula karakteristik dari sistem yaitu, komponen atau elemen (Component), batas sistem (boundary), lingkungan luar sistem (Environment), penghubung (Inteface), masukan (input), pengolah (process), keluaran (output), sasaran (objective), dan tujuan (goal) Jogiyanto (2008).

\section{Pengertian Sparepart}

Sparepart adalah suatu barang yang terdiri atas beberapa komponen yang membentuk satu kesatuan dan mempunyai fungsi tertentu. Seperti yang kita ketahui bahwa ada dua macam suku cadang yang di gabung menjadi satu kalimat pendek yaitu aspal (asli tapi palsu). Jika dilihat dari segi harga, suku cadang aspal jauh lebih murah ketimbang original. 
Penggunaan suku cadang aspal juga membuat performa kendaraan berkurang. Selai itu penggunaan BBM juga dirasa lebih boros.

\section{Pengertian Web browser}

Web browser adalah suatu program atau software yang dikhususkan untuk dapat mengakses dan melihat isi dari website yang diakses di internet.Browser yang saat ini paling banyak digunakan adalah Internet Explorer dan Mozilla Firefox (Anonimus, 2007:7).

\section{Pengertian Webserver}

Web server atau server web adalah sebuah bentuk server yang kusus digunakan untuk menyimpan halaman website atau home page. ( Nugroho, 2004:4)

\section{MySQL}

Risnandar (2013) mengemukakan MySQL adalah basis data yang bersifat open source sehingga banyak digunakan didunia. MySQL juga mengenal beberapa tipe data antara lain :

1. Tipe Data Numerik

MySQL dapat menerima masukan berupa angka-angka yang dibagi atas integer (angka tanpa pecahan) dan floating-point (angka dengan pecahan).

2. Tipe Data Karakter

Merupakan deretan huruf yang membentuk kata yang diapit oleh tanda petik tunggal (") atau tanda petik dua ("')).

3. Tipe Data Waktu

Merupakan data yang berisi tanggal (date) dan jam (time).

\section{PHP}

PHP adalah bahasa server-side scripting yang menyatu dengan HTML untuk membuat halaman web yang dinamis. Maksud dari server-side scripting adalah sintaks dan perintah-perintah yang diberikan akan sepenuhnya akan dijalankan diserver tetapi disertakan pada dokumen HTML. Pembuatan web ini merupakan kombinasi antara php sendiri sebagai bahasa pemrograman dan HTML sebagai pembangun halaman web (Sunarfrihantono, 2002:23)..

\section{Sistem Basis Data}

Sistem basis data adalah suatu sistem menyusun dan mengelola record-record menggunakan computer untuk menyimpan atau merekam serta memlihara data operasional lengkap sebuah organisasi atau perusahaan sehingga mampu menyediakan informasi yang optimal yang diperlukan pemakai untuk proses pengambilan keputusan ( Linda Marlinda,2004:1)

\section{UML}

Menurut Arief Ikhwan (2011), UML (Unified Modeling Language) adalah sebuah bahasa untuk menetukan, visualisasi, kontruksi, dan mendokumentasikan artifact (bagian dari informasi yang digunakan atau dihasilkan dalam suatu proses pembuatan perangkat lunak. Artifact dapat berupa model, deskripsi atau perangkat lunak) dari system perangkat lunak, seperti pada pemodelan bisnis dan system non perangkat lunak lainnya. UML merupakan suatu kumpulan teknik terbaik yang telah terbukti sukses dalam memodelkan system yang besar dan kompleks.

\section{METODE PENELITIAN Jenis dan Sumber Data}

Jenis data yang dilakukan oleh peneliti adalah data sekunder dimana data tersebut didapatkan dari hasil pengambilan dokumen. Sedangkan untuk sumber data 
sendiri peneliti khususkan tempat dimana peneliti jadikan objek penelitian yaitu pada CV. Lion Ternate.

\section{Metode Pengumpulan Data}

Metode pengumpulan data yang digunakan dalam penelitian ini yaitu dengan mengambil dokumen dari admin pada bengkel CV. LION.

\section{Alat dan Bahan}

Software yang digunakan

1. Sistem Operasional Windows7

2. MySQL untuk database

3. PHP (Hypertext Preprocessor) untuk mengolah suatu data dan mengirimkannya kembali ke web browser menjadi kode HTML.

4. Xampp (sebagai server untuk mengeksekusi fungsi yang ada dalam halaman website yang telah di buat, sekaligus menampilkan halaman website tersebut agar bisa diakses oleh user).

5. Notepad++ ( digunakan untuk membuat code editor (software penyunting kode, juga dapat mempermudah pengguna saat mengedit kode HTML dan kode CSS).

6. HTML (HyperText Markup Language) untuk bahasa pemograman

7. Microsoft Visio untuk membuat Flowchart. UML

Hardware yang digunakan

1. Laptop Acer Intel Inside

2. Keyboard

3. Mouse Optik

4. Printer canon Mp 230

5. Ram 2 GB

6. HDD $320 \mathrm{~GB}$

\section{Analisa sistem yang berjalan}

Analisa sistem yang sedang berjalan pada CV. LION dapat dideskripsikan pada gambar sebagai berikut

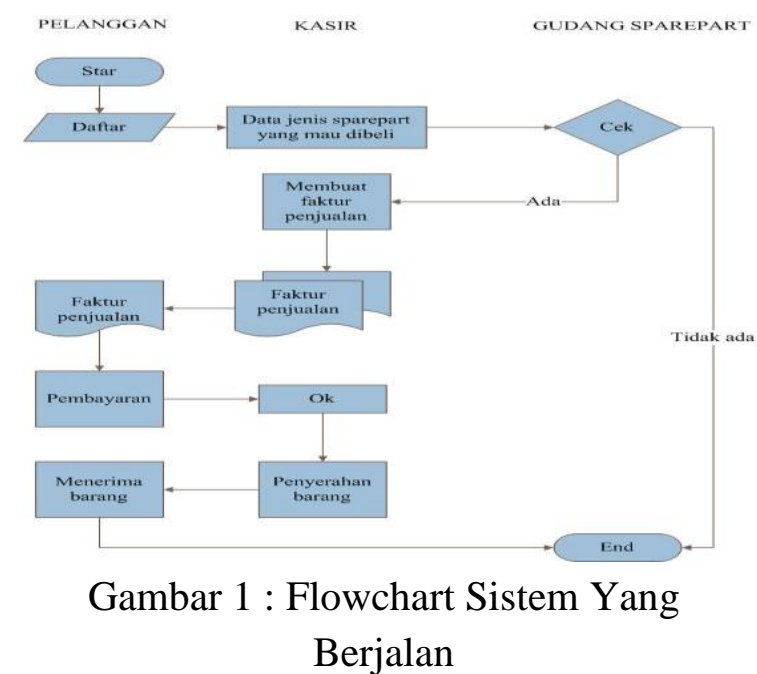

\section{Analisa System yang di usulkan}

Analisa sistem yang diusulkan dapat di deskripsikan pada gambar flowchart sebagai berikut::

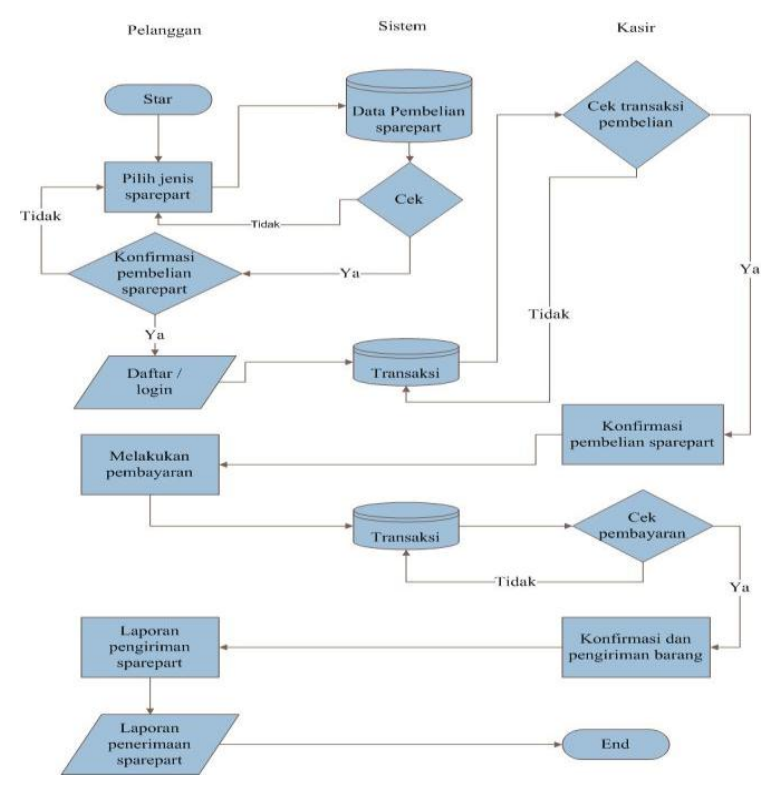

Gambar 2 : Flowchart Sistem Yang diusulkan

\section{PERANCANGAN SISTEM}

Mulyanto (2009) mengemukakan bahwa untuk mendapatkan pengembangan sistem informasi yang berkualitas, diperlukan prosedur-prsedur perancangan sesuai dengan pengembangan system 
informasi. Perancangan ssistem informasi terdiri dari dua aktivitas utama, yaitu perancanga perangkat keras meliputi perancangan arsitektur serta perancagan perangkat lunak yang meliputi perangkat database yang berupa ERD dan perancangan sistem yang dapat berupa DFD

\section{Use Case Diagram}

Usecase adalah abstraksi dari interaksi antara system dan actor. Use case bekerja dengan cara mendeskripsikan tipe interaksi antara user sebuah system dengan sistemnya sendiri melalui sebuah cerita bagaimana sebuah system dipakai, berikut merupakan gambar use case diagram system penjulan sparepart pada CV Lion sebagai berikut:

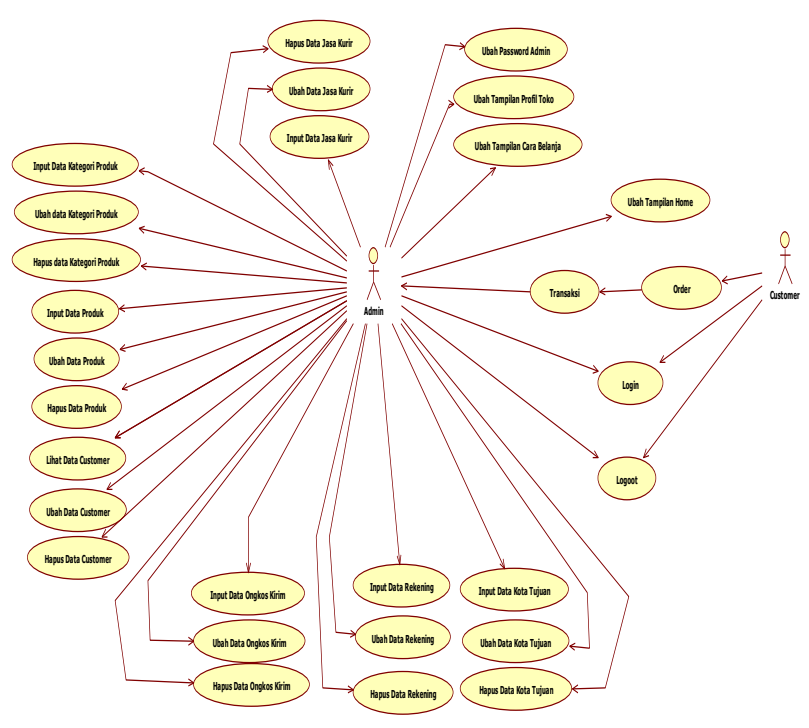

Gambar 3 : Use case Diagram Sistem

\section{Relasi Tabel}

Relasi tabel merupakan suatu hubungan antar tabel yang saling berkaitan, pada sistem ini ada beberapa tabel yang saling berhubungan satu sama lain. Hubungan antar tabel ini dihubungkan dengan field kunci utama (primeri key) dan field kunci tamu (forign key), field kunci utama dalam tabel pada sistem ini yaitu field yang berada pada bagian pertama tabel dihubungkan dengan bagian yang selain dari baris pertama dalam tabel. Seperti yang digambarkan pada gambar berikut:

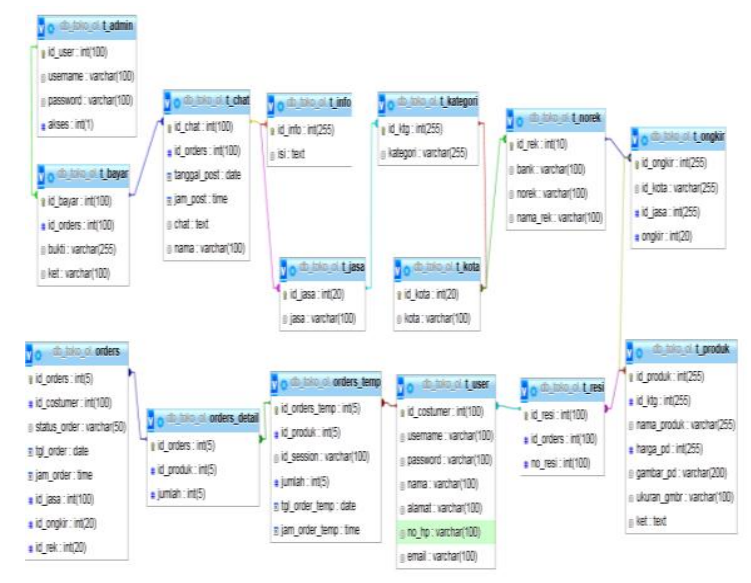

Gambar 4 : Use case Diagram Sistem

\section{Perancangan Tabel \\ Tabel Admin}

Tabel Admin digunakan untuk menyimpan data - data yang berhubungan dengan Admin. Spesifikasi dari tabel Admin sebagai berikut :

Tabel 1: Admin

\begin{tabular}{|l|c|c|l|l|}
\hline Filed & Type & $\begin{array}{c}\text { Leng } \\
\text { th }\end{array}$ & $\begin{array}{c}\text { Primary } \\
\text { Key }\end{array}$ & $\begin{array}{c}\text { AutoIncre } \\
\text { ment }\end{array}$ \\
\hline $\begin{array}{l}\text { Id_use } \\
\text { r }\end{array}$ & Int & 100 & $*$ & $*$ \\
\hline $\begin{array}{l}\text { Userna } \\
\text { me }\end{array}$ & $\begin{array}{c}\text { Varc } \\
\text { har }\end{array}$ & 100 & & \\
\hline $\begin{array}{l}\text { Passw } \\
\text { ord }\end{array}$ & $\begin{array}{c}\text { Varc } \\
\text { har }\end{array}$ & 100 & & \\
\hline Akses & Int & 1 & & \\
\hline
\end{tabular}

\section{Tabel Pembeli}

Tabel Pembeli digunakan untuk menyimpan data Pembeli, dan spesifikasi dari tabel Pembeli adalah sebagai berikut :

Tabel 2: Pembeli

\begin{tabular}{|c|c|c|c|c|}
\hline Field & Type & $\begin{array}{c}\text { Leng } \\
\text { ht }\end{array}$ & $\begin{array}{c}\text { Primary } \\
\text { Key }\end{array}$ & $\begin{array}{c}\text { AutoIncre } \\
\text { ment }\end{array}$ \\
\hline id_Pem & Int & 100 & $*$ & $*$ \\
\hline
\end{tabular}




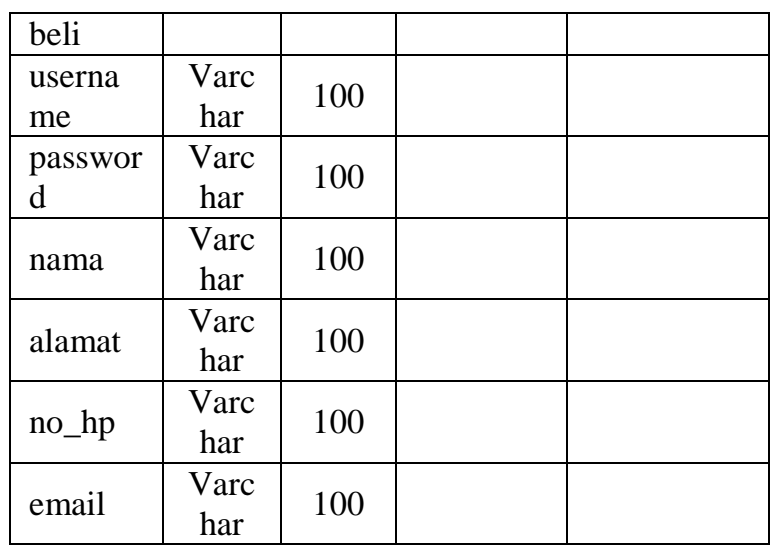

\begin{tabular}{|l|c|c|l|l|}
\hline ir & & & & \\
\hline id_rek & Int & 20 & & \\
\hline
\end{tabular}

\section{IMPLEMENTASI SISTEM}

\section{Form Utama (Home Page)}

Form utama (home page) digunakan untuk menampilkan halaman index atau halaman utama pada saat sistem ini diakses. Tampilan dari form utama (home page) ialah sebagai berikut :

\section{Tabel Produk}

Tabel produk digunakan untuk menyimpan data produk yang diinput oleh Admin, dan spesifikasi dari tabel produk adalah sebagai berikut:

Tabel 3; Produk

\begin{tabular}{|l|c|c|c|c|}
\hline \multicolumn{1}{|c|}{ Field } & $\begin{array}{c}\text { Typ } \\
\text { e }\end{array}$ & $\begin{array}{c}\text { Len } \\
\text { ght }\end{array}$ & $\begin{array}{c}\text { Primary } \\
\text { Key }\end{array}$ & $\begin{array}{c}\text { AutoIncre } \\
\text { ment }\end{array}$ \\
\hline id_produk & Int & 255 & $*$ & $*$ \\
\hline id_ktg & Int & 255 & & \\
\hline $\begin{array}{l}\text { nama_pro } \\
\text { duk }\end{array}$ & $\begin{array}{c}\text { varc } \\
\text { har }\end{array}$ & 255 & & \\
\hline harga_pd & Int & 255 & & \\
\hline $\begin{array}{l}\text { gambar_p } \\
\text { d }\end{array}$ & $\begin{array}{c}\text { varc } \\
\text { har }\end{array}$ & 200 & & \\
\hline $\begin{array}{l}\text { ukuran_ga } \\
\text { mbar }\end{array}$ & $\begin{array}{c}\text { varc } \\
\text { har }\end{array}$ & 100 & & \\
\hline ket & text & & & \\
\hline
\end{tabular}

\section{Tabel Orders}

Tabel orders digunakan untuk menyimpan data orders, dan spesifikasi dari tabel orders adalah sebagai berikut :

Tabel 4: Order

\begin{tabular}{|l|c|c|c|c|}
\hline \multicolumn{1}{|c|}{ Field } & Type & $\begin{array}{c}\text { Leng } \\
\text { ht }\end{array}$ & $\begin{array}{c}\text { Primary } \\
\text { Key }\end{array}$ & $\begin{array}{c}\text { AutoIncre } \\
\text { ment }\end{array}$ \\
\hline $\begin{array}{l}\text { id_order } \\
\text { s }\end{array}$ & Int & 5 & $*$ & $*$ \\
\hline $\begin{array}{l}\text { id_Pem } \\
\text { beli }\end{array}$ & Int & 100 & & \\
\hline $\begin{array}{l}\text { status_o } \\
\text { rder }\end{array}$ & $\begin{array}{c}\text { Varc } \\
\text { har }\end{array}$ & 50 & & \\
\hline $\begin{array}{l}\text { tgl_orde } \\
\text { r }\end{array}$ & date & & & \\
\hline $\begin{array}{l}\text { jam_ord } \\
\text { er }\end{array}$ & time & & & \\
\hline id_jasa & Int & 100 & & \\
\hline id_ongk & Int & 20 & & \\
\hline
\end{tabular}

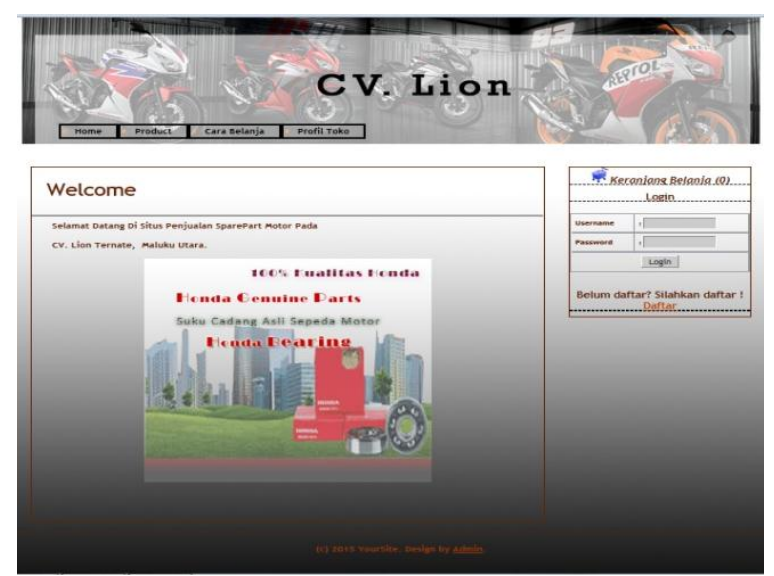

Gambar 5 : Form menu utama

\section{Form Data Pembeli}

Pada halaman ini merupakan tampilan berita dan informasi, pengunjung dapat melihat berita dan informasi

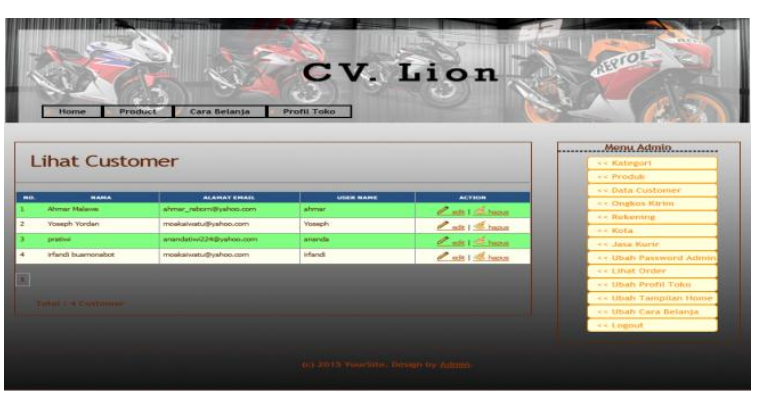

Gambar 6 : data pembeli

\section{Form Registrasi Pembeli}

Pada halaman ini, pembeli dapat mengisi biodata diri agar terdaftar pada sistem, dan itu menjadi akun pribadi pembeli untuk dapat masuk ke dalam 
sistem. Tampilan dari form registrasi pembeli adalah sebagai berikut

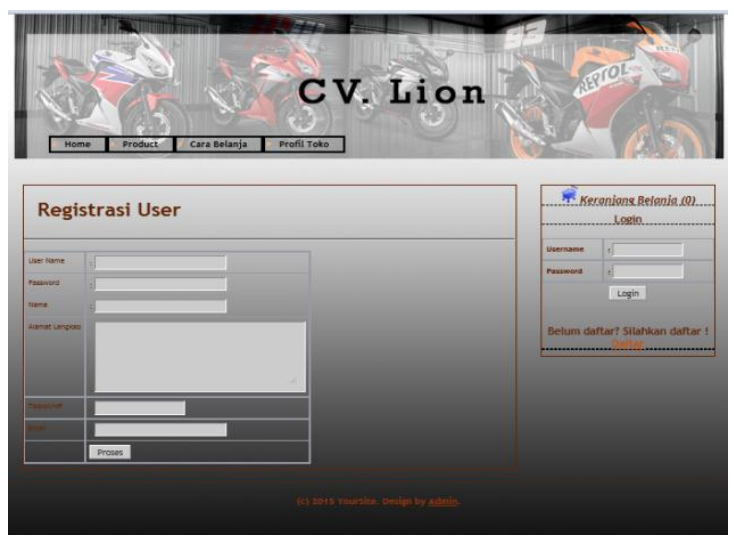

Gambar 7 : Form registrasi pembeli

\section{Form Produk Sparepart Motor}

Pada tampilan produk, pembeli dapat melihat - lihat terlebih dahulu produk apa yang ingin dibeli, jika pembeli sudah dapat barang yang dicari maka pembeli klik pada build the item yang letaknya berada di bawah produk yang ingin di beli, dan tampilan dari halaman form produk adalah sebagai berikut:
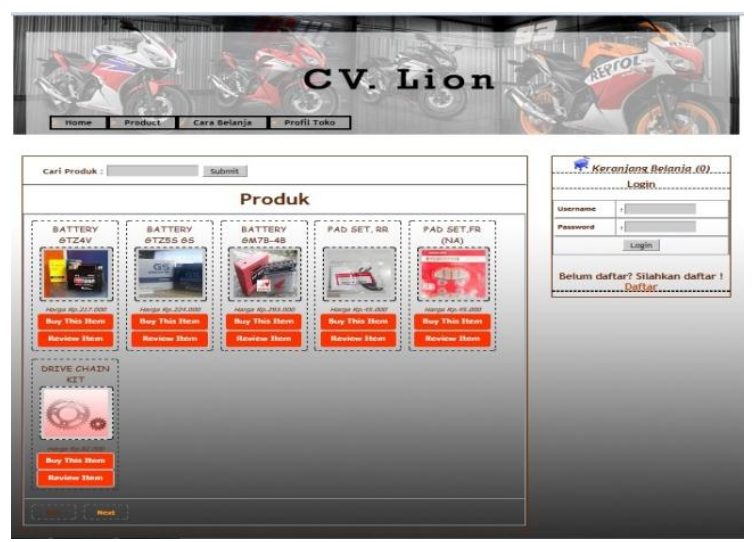

Gambar 8 : Produk sparepart motor

\section{Form Detail Order}

Pada form detail order, pembeli dapat melihat orderannya secara detail dan pada form ini juga pembeli bisa upload bukti pembayaran ke sistem, dan pembeli juga bisa melakukan tanya jawab dengan Admin melalui sistem ini untuk, dan tampilan form detail adalah sebagai berikut:

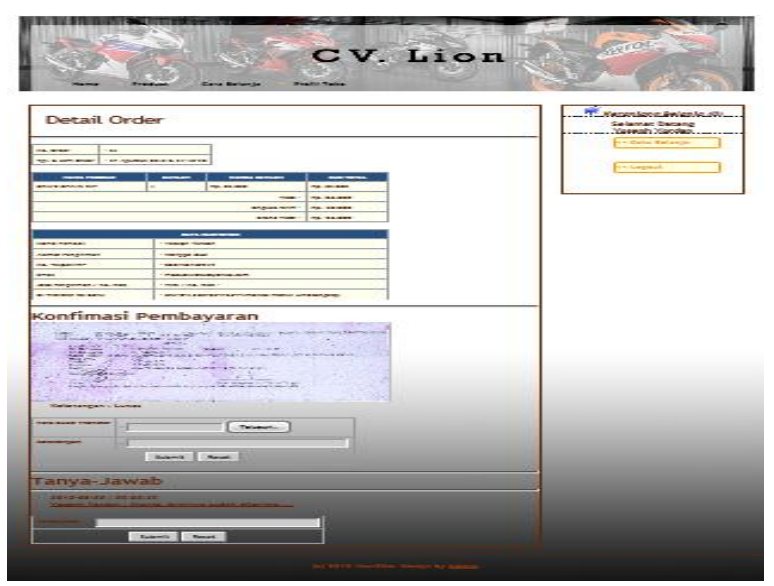

Gambar 9 : Form detail order

\section{KESIMPULAN}

Setelah melakukan perancangan sampai pada tahap implementasi "Perancangan Sistem Informasi Penjualan Sparepart Motor Berbasis Web Pada CV.Lion" dapat disimpulkan bahwa: 1). Perancangan Sistem Informasi Penjualan Sparepart Motor Berbasis Web Pada CV. Lion, dirancang menggunakan beberapa aplikasi pendukung seperti: Noteppad ++, Xampp, UML, php My Admin, Dreamweaver. Harapan peneliti semoga sistem yang sudah di rancang ini dapat mempermudah admin dalam melakukan proses penjualan sparepart motor, dan memudahkan admin dalam proses pencarian data sparepart motor. 2). Perancangan sistem informasi penjualan sparepart motor berbasis web pada CV. Lion juga sangat membantu masyarakat, terutama dalam mengakses informasi, juga dalam proses pembelian sparepart motor.

Berdasarkan kesimpulan di atas, maka diajukan saran sebagai berikut.: 1) Diharapkan, Perancangan Sistem Informasi Penjualan Sparepart Motor 
Berbasis Web pada CV. Lion ini dapat diterapkan untuk menggantikan sistem yang lama. 2) Perancangan Sistem Informasi Penjualan Sparepart motor berbasis web yang telah dibuat ini masih belum sempurna. sistem ini dapat dikembangkan oleh peneliti-peneliti selanjutnya.

\section{DAFTAR PUSTAKA}

Nugroho, Bunafit. Trik dan Rahasia Membuat Aplikasi Web dengan PHP, Yogyakarta: Penerbit Gava Media, 2007

Nugroho, Bunafit. LatihanMembuat Aplikasi Web PHP dan MySQL dengan Dreamweaver MX $(6,7,2004)$ dan 8, Yogyakarta: Penerbit Gava Media, 2008

Marlinda, Linda. 2004. Sistem Basis Data. Yogyakarta, Andi.

Bambang Eka Purnama (2013), Membangun Toko Online Dengan WP Commerce, Graha Ilmu, Yogyakarta

Puspita Dwi Astuti, Ramadian Agus Triyono, Sistem Informasi Penjualan Obat Pada Apotek Jati Farma Arjosari, IJCSS) 15 - Indonesian Jurnal on Computer Science Speed FTI UNSA Vol 10 No 1 - Februari 2013 - ijcss.unsa.ac.id, ISSN 1979 933

Priyo Sujarwo, Pembuatan Website Penjualan Barang Pada CV. Anandam Computer Yogyakarta, IJNS Indonesian Journal on Networking and Security - Volume 3 No 2- 2014, ISSN: 2302-5700 (Print) 2354-6654 (Online)

Siska Luluus Adi Permana, Sistem Informasi Penjualan Dan Pembelian Spare Part Handphone Pada Toko ECell, IJNS - Indonesian Journal on Networking and Security - Volume 3
No 3 - Juli 2014, ISSN: 2302-5700

(Print) 2354-6654 (Online) 